\title{
História e Pensamento Hermenêutico na Alemanha do século XX
}

João Carlos de Oliveira Luna*

\section{Resumo}

O artigo que se vai ler pretende apresentar de forma superficial, esboçando um panorama de produção do conhecimento no âmbito das ciências sociais, através de uma conexão ensaística entre os pensadores alemães que se voltaram em suas escritas para o problema da hermenêutica, com base nas discussões recentes sobre história e interpretação. Iniciando a discussão a partir das considerações do filólogo e filósofo, Friedrich Schleiermacher e finalizando em atenção ao diálogo conceitual do historiador Reinhart Kosellek, numa tentativa de demonstrar uma tradição alemã de discussão escrita sobre o método hermenêutico e sua atual relação com a escrita da história.

Palavras-Chaves: conhecimento, interpretação, história e hermenêutica.

\begin{abstract}
This current article has the objective of present from a superficial form, sketching the landscape of knowledge production within the social sciences, essays through a connection between German thinkers that directed their writings to the problem of hermeneutics, based on recent discussions about history and interpretation. Beginning the discussion from considerations of the philologist and philosopher Friedrich Schleiermacher and finalizing in attention to the conceptual dialogue of the historian Reinhart Kosellek, as a trying of demonstrating a germane tradition of writing discussion about the hermeneutic method and his actual relation with the writing of the history.
\end{abstract}

Key-Words: knowledge, interpretation, history and hermeneutic.

\section{A busca hermenêutica da apreensão de sentido na escrita}

\begin{abstract}
"O sentido está tão enraizado no que é terreno, que se faz mister uma força igual para erguê-lo dali". ${ }^{1}$
\end{abstract}

G.W.F. Hegel

Nos dias atuais, a hermenêutica (na etimologia deriva do grego: Hermes) caminha para se tornar o método de interpretação textual de maior aceitação entre as comunidades cientificas, quando se tratando do âmbito de produção do conhecimento das "ciências humanas" (do alemão Geisteswissenschaften). Atualmente é representada como suporte teórico e filosófico imprescindível para o alcance da tão desejada e interminável renovação das ciências. Em específico, a hermenêutica é sempre pensada como um eminente campo ${ }^{2}$ de produção do saber que está sujeito a se tornar parte metodológica da produção

\footnotetext{
* Graduado em História pela Universidade Federal de Campina Grande-PB (UFCG), sob orientação do Prof. Dr. Gervácio Aranha. Atualmente é pesquisador, nível de Pós-Graduação (Mestrado) pela Universidade Federal de Pernambuco (UFPE), onde desenvolve pesquisas, sob orientação da Prof(a). Dra. Isabel C. M. Guillen, que relacionam a música contemporânea e a produção do conhecimento histórico.

${ }^{1}$ Cf. HEGEL. G.W.F. Fenomenologia do Espírito. Trad. Paulo Meneses. 2a Edição. Rio de Janeiro: Vozes, 1992. pp. 25.

2 Relacionado à produção textual de alguns teóricos alemães - Schleiermarcher, Dilthey, Weber, Gadamer, Heidegger, Habermas e Koselleck - que problematizaram os legados da teoria e da filosofia hermenêutica. Seria, sobretudo, a historicidade recorrente de referenciar atuações "hermeneutas"?
} 
de conhecimento das ciências sociais. Suas considerações envolvem os domínios - em teoria, metodologia, interpretação e ética histórica -, da filosofia crítica, da história, da sociologia, da lingüística e da fenomenologia ${ }^{3}$, sendo habitualmente utilizada de forma ética e dialética na busca da apreensão de sentido na escrita, com base no distanciamento da pressuposição de uma "linguagem universal".

Indiscutivelmente, na contemporaneidade, os grandes colaboradores da formulação do pensamento hermenêutico foram pensadores alemães e franceses que problematizando a escrita e a leitura, a explicação e a compreensão, o homem e a história, apresentaram discursivamente para os atuais pesquisadores, importantes considerações para se estudar a linguagem e a sociedade. Dessa forma, cabe ressaltar que tal estudo se apóia, sobretudo, na produção escrita de alguns pensadores alemães, traduzida e correlacionada referencialmente ao estudo da hermenêutica - o que indica uma leitura superficial de algumas obras consideradas relevantes para observação da apropriação e uso da hermenêutica na produção de conhecimento das ciências sociais. Contudo, a possível abordagem hermenêutica no âmbito das ciências sociais pode ser diversa - a título de determinado campo do saber ser ampliado ou reduzido -, quando observado a produção de vários pesquisadores que a utilizam de forma crítica e singular nas especificidades concernentes a dimensão interpretativa de suas escritas.

As evidências bibliográficas aqui utilizadas demonstram que a dimensão do conhecimento hermenêutico é ampla e pode também ser atribuída a setores mais específicos do saber, como a exemplo de atividades centradas no campo da "hermenêutica bíblica" e da "hermenêutica jurídica". As referências teóricas dos autores das obras estudadas formulam proposições em torno da busca de sentido na escrita, com base no seu valor simbólico e nos métodos relacionados à interpretação na apreensão de sentido de textos diversos. Torna-se importante ressaltar que, a priori, a hermenêutica tratava-se fundamentalmente da produção do saber com base na interpretação de textos bíblicos e filosóficos. Aqui, o âmbito referencial de discussão será de alguns

\footnotetext{
${ }^{3}$ Nesse sentido uma "hermenêutica fenomenológica", aquilo que Emmanuel Carneiro Leão, em leitura de Heidegger chama de, "conjecturas da existência em sua estrutura de articulação". HEIDEGGER, Martin. Ser e Tempo. Trad. Maria Sá Cavalcante Schuback. 12ª Edição. Universidade São Francisco: Editora Vozes, 2002. p. 20.
} 
autores alemães da contemporaneidade e suas respectivas proposições que envolvem a hermenêutica no âmbito central da produção do saber histórico ${ }^{4}$.

Inclusive, cabe ressaltar que a hermenêutica não é um conhecimento recente, as discussões contemporâneas mostram uma base teórica referencial no seu saber que remonta as proposições filosóficas dos antigos gregos (Hermes). Trata-se de uma releitura de suas proposições históricas - que vão desde a Grécia, passando pelas discussões sobre as técnicas de interpretações dos textos cristãos até na época do Renascimento, quando se "fixa" em três tipos básicos de representação: "sacra", "profana" e "júris" - que ocupam fundamentalmente o campo de discussão da linguagem na religião, filosofia e ciências jurídicas. Na Alemanha do século XIX, o filólogo e filósofo Friedrich Schleiermacher envolve a hermenêutica no cerne de suas discussões, ${ }^{5}$ a exemplo da publicação de título, Hermenêutica e Crítica [Hermeneutik und Kritik], de 1838. Como o nome indica, o autor passou a considerar a hermenêutica como método eficaz de interpretação - na apreensão de sentido - que vê na dialética seu suporte crítico inicial, o diálogo estabelece-se com base na reflexão "sobre as relações entre o universal e o particular". 6

\footnotetext{
${ }^{4}$ Em lembrança ao que sugere Gadamer, "ver na consciência histórica não um fenômeno radicalmente novo, mas uma transformação relativa, se bem que "revolucionária", no interior daquilo que, desde sempre, constituiu o homem em face de seu passado. Trata-se, em outros termos, de se familiarizar com o papel que a tradição desempenha no interior do comportamento histórico, e indagar sobre sua produtividade hermenêutica". GADAMER, Hans-Georg. 0 problema da consciência histórica. Org. Pierre Fruchon. Trad. Paulo César Duque Estrada. Rio de Janeiro: Editora Fundação Getúlio Vargas, 1998. pp. 29.

5 Observar como a partir de Schleiermacher, com seu trabalho em foco discursivo da hermenêutica como metodologia, as fragmentações discursivas e de apropriação são diversas e podem ser lidas nos caminhos da teoria hermenêutica, filosofia hermenêutica e hermenêutica crítica. Ou seja, a determinação da "metodologia hermenêutica" parte na "fixação" da linguagem das indicações reflexivas de Schleiermarcher. Cf. SCHLEIERMACHER, Friedrich D.E. Hermenêutica: Arte e técnica da interpretação. Trad. Celso Reni Braida. $3^{\text {a }}$ Edição, Petrópolis RJ: Vozes, 1999. Pag. 7-9.

${ }^{6}$ Expresso romanticamente para aludir ao "espírito idealista de seu tempo". Embora, seu legado escrito envolva 0 "idealismo" com o "realismo", sobretudo, o ideal com o historico. Cf. SCHLEIERMACHER, 1999. Pag. 13
} 
Tal método de interpretação proposto por Schleiermacher, que romanticamente condiciona "toda produção de expressão humana como situada em um horizonte lingüístico", 7 trabalha em busca de sentido na interpretação textual com inspiração também na inseparabilidade de leitura entre o sujeito (autor) e objeto (obra). Schleiermacher, acreditava que o desenvolvimento da prática hermenêutica - crítica, teórica e filosófica seria capaz de restabelecer os princípios

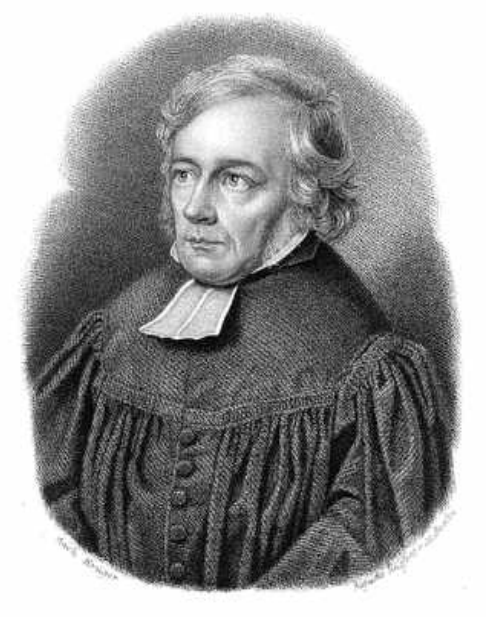

** Friedrich Schleiermacher (1768-1834) gerais de toda e qualquer leitura e compreensão das manifestações da linguagem, enxergando na hermenêutica uma metodologia e uma arte estética, ou seja, um estudo de dimensãosobre as formas e sentidos, sobretudo a questão de como o homem se manifesta e é lido em aparência - de sentidos do texto escrito.

Dentre as muitas contribuições de Schleiermacher, para o aprimoramento e aplicabilidade do pensamento hermenêutico nas ciências sociais, estão idéias e reflexões sobre a circularidade interpretativa entre o todo e o particular da escrita. Podendo ressaltar também a dependência textual constitutiva entre a parte e a totalidade em uma tentativa de "impossibilitar" a fomentação da "compreensão" por mera indução. Outra questão recorrente em Schleiermacher é que, através da relação entre a dialética e a hermenêutica, interpreta-se que "o homem" nunca conhece a "coisa em si", mas estetiza as coisas com uma singular e simbólica capacidade de subjetividade, uma "poética" como complemento do conhecimento, razão.

Para Schleiermacher, torna-se imprescindível a "inseparabilidade entre o pensamento e linguagem", ${ }^{8}$ e esboça através de discussões uma múltipla relatividade de pontos de vista. Ou seja, apresentando a idéia da impossibilidade de se existir uma linguagem universal, o autor de

\footnotetext{
7 Perceber que o resultado da "compreensão" em Schleiermacher é fixada sob o horizonte da história e da linguagem, que remetem fundamentalmente aquilo mesmo que deve ser compreendido. Cf. SCHLEIERMACHER, 1999. Pag. 8.

8 Em Schleiermacher a própria linguagem é fonte de relatividade limitada em sua pretensão de universalidade. Cf. SCHLEIERMACHER, 1999. Pag. 11.
} 
Hermenêutica: Arte e Técnica da Interpretação, sugere atenção para o pesquisador - aquele que deseja utilizar-se da hermenêutica em seus caminhos -, conhecer os gêneros narrativos, antes mesmo de iniciar tal obstinação escrita.

Schleiermacher tomando a linguagem como a própria fonte de relatividade do pensamento, ${ }^{9}$ propõe que a compreensão avança na medida em que se comparam textos pesquisados e encontram divergências que indiquem possibilidades de diferentes leituras. Foi assim, que o filósofo alemão Wilhelm Dilthey, com base em leituras diversas dos escritos de Schleiermacher, se preocupou em reformular as considerações da metodologia da hermenêutica, tornando-as válidas e seriamente utilizáveis para o campo das "ciências humanas", poder-se-ia dizer que ao se constituir como "legítimas ciências empíricas". ${ }^{10}$ Seu grande passo foi diferenciar a metodologia de aplicação nos estudos das "ciências do espírito" do modelo da metodologia "positivista" das "ciências naturais".

\section{A reprodutibilidade da hermenêutica: por uma "objetividade" do saber nas ciências sociais}

Dilthey, em sua obra intitulada "Introdução às Ciências do Espírito" (1883), esboça a "Crítica da razão histórica", que vê na leitura hermenêutica a possibilidade de proporcionar uma nova formulação para o "conhecimento científico", enfatizando principalmente as considerações das divergências entre os

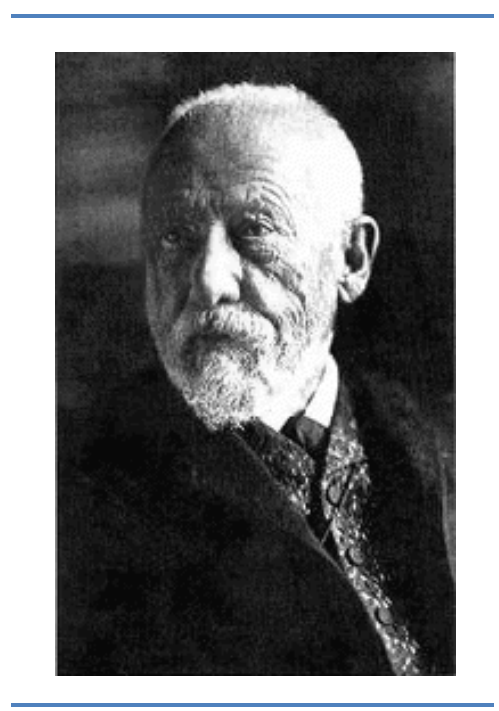

** Dilthey, Wilhelm (1833 - 1911) aspectos específicos do "homem" e da

\footnotetext{
9 Perceber que para Schleiermacher, "sem linguagem não se daria nenhum saber, e sem saber nenhuma linguagem". Cf. SCHLEIERMACHER, 1999. Pag. 12.

10 Estudar que nesse tempo histórico, busca-se concomitantemente assegurar um "fundamento à filosofia", que vê no idealismo de Hegel, um caminho plausível para o empreendimento filosófico, exemplo do trabalho de Dilthey, em interpretação da leitura de Gadamer, que sugere a historicidade do sujeito como delimitadora da objetividade do conhecimento histórico. Pois, na consciência histórica "é a própria filosofia que está em questão, na totalidade de suas pretensões". GADAMER, 1998. Pag. 20.
} 
"natureza", com vista em delimitar ${ }^{11}$ horizontes de discussões das "ciências naturais" e das "ciências humanas". Para Dilthey, a "dimensão poética" da linguagem é "característica" dos homens, considerando o significado de metáfora - "poesis" do Grego, semelhante à idéia de "transportar" - ele enxergou o olhar humano como constituinte de uma "paisagem"; a exemplo de um estudo sobre a cidade em que passa a ser constituída ao pesquisador a partir da leitura dos escritos que os homens, que lá vivem ou a viram em algum momento, fizeram sobre ela.

Nas proposições de Dilthey, para os estudos das Geisteswissenschaften, não há possibilidade de se abrir mão da "dimensão poética", da "histórica" e da "vida", na produção do conhecimento. As considerações do pensador alemão enfocam que, a "experiência humana" é um suporte para se alcançar a "objetividade" do conhecimento da também chamada "ciências do espírito". É a partir da leitura dada por Dilthey, que a hermenêutica como suporte interpretativo e metodológico das ciências sociais e produz novos enfoques e aperfeiçoamentos das proposições iniciais determinadas por Schleiermacher. Só a título de esclarecimento, a idéia de "circularidade da ciência" como inicialmente proposta por Schleiermacher, é reinterpretada nas proposições de Dilthey, onde só pode-se determinar a "compreensão" pelo "sentido" e o "sentido" pela "compreensão".

Wilhelm Dilthey, na busca de um "sentido textual', pergunta não só sobre a escrita do autor, mas também sobre sua vida, representando a interação da hermenêutica no âmbito das ciências sociais, não somente no campo da linguagem, como inicialmente tratou Schleiermacher de forma individual, mas também na leitura da sociedade, da vida e dos atores sociais. Em complementação textual do filósofo alemão Hans-Georg Gadamer, pode-se esclarece que, a partir de Dilthey:

\begin{abstract}
estabeleceu-se uma inteligibilidade própria das ciências humanas, compreensiva, distinta daquela das ciências naturais, explicativa, quantitativa e indutiva. Enquanto as ciências explicativas buscam determinar as condições causais de um fenômeno através da observação e da quantificação, as ciências compreensivas visam a apreensão das significações intencionais das atividades históricas concretas do homem. ${ }^{12}$ (GADAMER, 1998. Pag. 28)
\end{abstract}

\footnotetext{
11 Fazer esforço para ler "delimitar", com uma proximidade à idéia de "historicizar" ou "historicizante",

12 SCHLEIERMACHER, 1999. Pag. 8.
} 
Destarte, seguindo os pressupostos metodológicos da hermenêutica iniciados por Schleiermacher, as considerações filosóficas de Wilhelm Dilthey expressam ênfase na leitura da "essência poética" do homem, num vislumbre, onde a leitura do individual tem total relação com a possibilidade de compreensão do coletivo. Em Dilthey, as pessoas compreendem "o mundo", mediadas por valores diversos, as bases de suas experiências de vida. Contudo, dentre as grandes contribuições deste filósofo alemão para o estudo da hermenêutica, das quais se visualizam as pessoas inspiradas e alimentadas por uma "ética cultural histórica", o autor expressa também uma idéia de temperamento - um pensar historicamente - num dado tempo e lugar. Dilthey rompendo com toda possibilidade de naturalização do conhecimento, ficou muito conhecido academicamente pela difusão de suas idéias, dos finais do século XIX e início do século XX. Ė um dos pensadores "historicistas" com formulações de idéias herdeiras do idealismo alemão, a exemplo de sua influência nas proposições filosóficas de Hegel e Kant. Nas palavras de HansGeorg Gadamer.

o objetivo que se propõe Dilthey é manifesto: ele pretende descobrir, nos confins da experiência histórica e da herança idealista da escola histórica, um fundamento novo e epistemologicamente consistente; é isso que explica a sua idéia de completar a crítica da razão pura de Kant com uma "crítica da razão histórica. ${ }^{13}$ (GADAMER, 1998. Pag. 28)

Dilthey, valorizando a idéia de "tradição" e "permanência", trazendo a suposição de que a compreensão se dá pela empatia, pela paixão, ou seja, "sem afinidade não há compreensão", se utiliza da hermenêutica em associação com a idéia de continuidade histórica, e se volta para o aprimoramento dos conceitos de antropologia e etnografia. A maneira de escrita, a estrutura textual, as estéticas adotadas pelos estudiosos alemães aqui discutidos, foram formuladas e referenciadas em disciplina interpretativa, tomando como pressuposto anterior o questionando e pensamento não só sobre a história, mas sobre as áreas específicas do saber, que estruturam idéias e criam conceitos, como a exemplo da sociologia. Cria-se um tipo de

${ }^{13}$ Gadamer sugere que Ditthey como estudioso da "escola histórica" alemã (Ranke e Droysen), "ao introduzir o mundo histórico no desenvolvimento autônomo da razão, o idealismo especulativo passou a integrar 0 conhecimento histórico ao domínio do saber puramente racional. A história tornou-se um capítulo da enciclopédia do espírito". GADAMER, 1998. Pag. 29. 
inventário das diferenças onde o fato só existe sob conceito que o informa em um determinado lugar, em uma determinada temporalidade.

Um dos maiores colaboradores para o surgimento da sociologia foi o pensador alemão Marx Weber, que também se utilizou do conhecimento hermenêutico como forma de contribuição para o avanço de suas pesquisas. Weber caminhou próximo às idéias iniciadas por Dilthey, no sentido de discutir

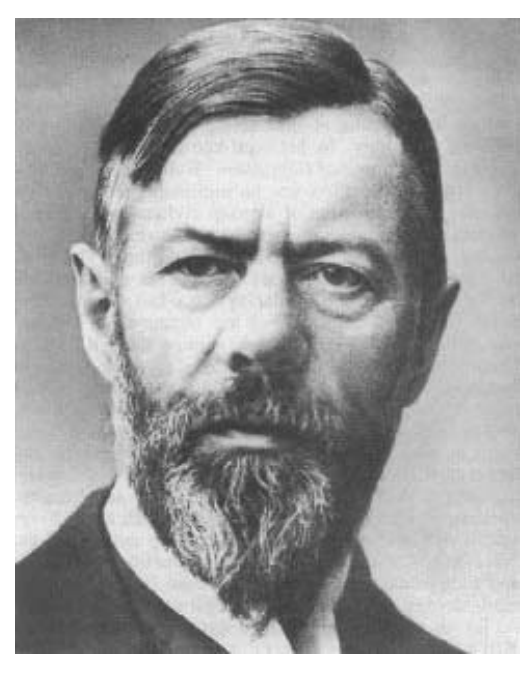

** Marx Weber (1864-1920) também a possibilidade de produção do conhecimento científico pelas ciências sociais. Max Weber se diferencia de Dilthey na discussão entre os tipos de "objetividades" do conhecimento produzido. Para o primeiro a "objetividade" só pode ser garantida através do discurso das ciências sociais, enxergando o conhecimento como uma produção artificial humana, que é aceito ou rejeitado através de convenções institucionais. Eis, a diferenciação principal entre o pensamento Weber e o de Dilthey, que enxergou a "objetividade" do discurso simplesmente a partir da individual empatia do pesquisador com o tema estudado.

Marx Weber observou uma possibilidade de se produzir "objetividade" de acordo com o conhecimento do objeto, do método da pesquisa utilizado e da historicidade das coisas, pois a temporalidade é um fator diferencial nas especificidades dos saberes. É a partir dele que as ciências sociais olham para o mundo de um determinado e justificado ponto de vista. Weber vê na idéia de "espírito" fomentada anteriormente por Dilthey, uma fórmula que "transcende" do individual. Com isso, a "objetividade" do conhecimento se dá principalmente através das regras, métodos e critérios que o pesquisador irá se utilizar em sua pesquisa. Contudo, são também as definições de métodos que produzem as instituições do saber.

Weber, por assim dizer, aprimora as condições metodológicas sugeridas inicialmente por Dilthey - para as ciências sociais -, e se atém à produção do conhecimento a partir do sujeito coletivo. Enquanto Dilthey se ateve na "objetividade" a partir do sujeito individual, com base na idéia de "experiência" e 
de "vida". Em Weber, as ciências sociais buscam sempre a renovação, sendo o conhecimento renovável e produzido principalmente através de releituras e de visões críticas dos textos clássicos, pois o "domínio do trabalho científico não tem por base as conexões "objetivas" entre as "coisas", mas as conexões conceituais entre os problemas". ${ }^{14}$ Através de uma discussão sobre a "ética" do conhecimento, Weber propõe - com a divulgação de uma revista - em lugar do "juízo de valor", tornar a ciência "consciente", com base no "conhecimento do significado" 15 daquilo que ela busca, colocando em cheque, a "objetividade" do conhecimento nas ciências sociais. Preocupado com a definição da especificidade, da dimensão do conhecimento e sua validade discursiva, Weber problematiza que:

Ao distinguir, em princípio, entre "juízos de valor" e "conhecimento empírico", pressupomos até agora a existência de uma modalidade de conhecimento de validade incondicional, ou seja, que efetivamente exista a ordenação, em pensamento, da realidade empírica no domínio das ciências sociais. Essa suposição torna-se agora um problema, na medida em que temos que explicar o que pode significar no nosso domínio a "vigência" objetiva da validade que procuramos. ${ }^{16}$ (WEBER, 2006. pp. 16)

É perceptível que o questionamento do alcance da capacidade empírica das ciências sociais, elaborado por Weber, esboce uma preocupação hermenêutica em suas proposições para o alcance da validade do conhecimento científico. Através de "uma interpretação histórica sob um ponto de vista específico". ${ }^{17}$ Não tão distante de Max Weber, outro grande pensador alemão que através da hermenêutica reinterpretou a produção do conhecimento filosófico de forma plausível para as ciência sociais foi o filósofo Martin Heidegger. Agora, com base na "Fenomenologia do Espírito" (1806) de Hegel e na obra "Zaratustra" (1883) de Friedrich Nietzsche. Heidegger prosseguiu com o Romantismo alemão com a publicação de seu livro "Ser e Tempo" (1927). Em Heidegger, a leitura e a compreensão do "ser" é relativa ao "tempo" e a uma historicidade. Com isso, para Heidegger, não faz nenhum "sentido" dizer que algo é "em definitivo", porque a própria concepção das coisas é temporal, ou seja, toda compreensão é de uma parte. Heidegger

14 WEBER, Marx. A "objetividade" do conhecimento nas ciências sociais. Trad. Gabriel Cohn. São Paulo: Ática, 2006. p. 38

${ }^{15}$ Cf. WEBER, 2006.

16 WEBER, 2006. Pag. 30

17 Op. Cit. pp. 34. 
defendia a idéia de que o "ser humano" é um "ser na linguagem", é um "ser no sentido", sendo a idéia de "ser" inseparável da condição lingüística e da narrativa histórica. $\mathrm{Na}$ hermenêutica de Heidegger, "a "universalidade" do ser "transcende" toda universalidade genérica. Segundo a terminologia medieval, 0 "ser" é um "transcendens"."18 Com isso, Martin Heidegger torna o conceito de "ser", como indefinível.

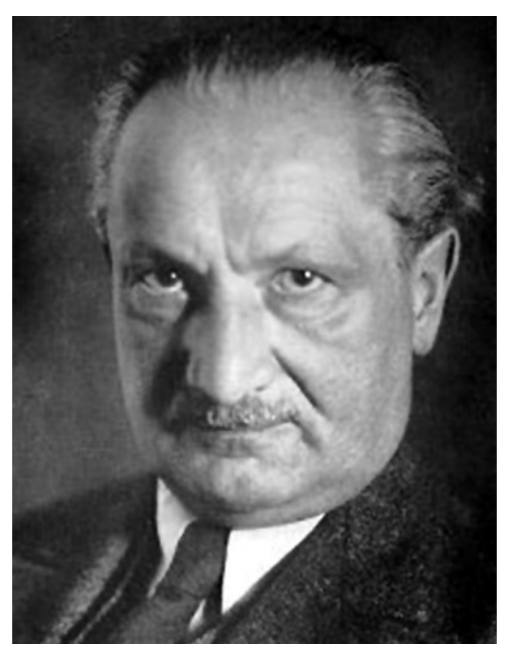

** Martin Heidegger (1889-1976)

\section{O lance de dardos hermenêuticos na história}

\section{que se olha através do espelho}

A hermenêutica, utilizada em Martin Heidegger, serve para fortalecer uma reflexão "ontológica" sobre o sentido do "ser" no "tempo". Tentando propor uma definição universal do "ser" que considere a fenomenologia e a hermenêutica ${ }^{19}$ como métodos plausíveis para sua fundamentação filosófica. 0 "ser" também é lido de forma particular e universal, como sugeria Schleiermacher ao propor a metodologia hermenêutica para a produção do conhecimento. Em resumo, Heidegger pressupõe a idéia de que o "ser" afirmase em vários sentidos, pois o "homem" é um "ser" no "tempo", e dessa forma se metamorfoseia com ele. O autor ao esboçar significado sobre o "ser", esclarece que:

em cada um dos seus modos de ser e, por conseguinte, também em sua compreensão do ser, a pre-sença sempre já nasceu e cresceu dentro de uma interpretação de si mesma, herdada da tradição. De certo modo e em certa medida, a pre-sença se compreende a si mesma de imediato a partir da tradição. Essa compreensão lhe abre e regula as possibilidades de seu ser. ${ }^{20}$ (HEIDEGGER, 2002. Pag. 48)

O "homem" em Heidegger é, sobretudo, um "ser" que "caminha para a morte" e sua relação com o mundo - mundanidade - concretiza-se a partir dos seus conceitos e valores herdados de uma "tradição", que são completamente

${ }^{18}$ Cf. HEIDEGGER, 2002. p. 28.

${ }_{19}$ Nesse sentido, torna-se relevante esclarecer que em Heidegger, "a impossibilidade de se definir o ser não dispensa a questão de seu sentido, ao contrário, justamente por isso a exige". Op. Cit. p. 29.

20 HEIDEGGER, 2002. Pag. 48. 
associados ao "tempo" em que se vive. Distanciando-se das formulações "transcendentais" da filosofia metafísica para o "ser" no mundo, Heidegger pensa o "ser" em sua temporalidade de forma que indica pensar em um entendimento de sempre historicizar o "ser" na apreensão de sentido para a escrita. Pois, nas palavras do filósofo alemão, o "ser" é contraditório, mutável e abstrato. Tais considerações são de importância fundamental para se enxergar na obra de Heidegger algumas ressonâncias dos pensamentos propostos inicialmente por Dilthey, pois são as idéias de "historicidade" e "experiência de vida" que estão inseridas de forma mais contundente nas formulações de Heidegger sobre o problema do "ser".

Heidegger não nega as referências e como discípulo de Nietzsche, vê que o "homem" constrói o próprio "ser" motivado pelas suas inquietações e que se afirma ao longo da vida, ou seja, sendo e vivendo. $\mathrm{E}$, embora o pensamento de Heidegger possa ser associado em circunstâncias singulares com algumas considerações propostas por Wilhelm Dilthey, sobre o pensar a partir de um "tempo" e "espaço". Isso não quer dizer que, o "tempo" em Heidegger seja o "aspecto histórico do ser", mas a "ontologia histórica do ser", que é a de existir em um "tempo" e um "espaço". Sendo o "tempo", a condição circular hermenêutica de todas as coisas. Nas considerações do estudioso Gadamer, ao relacionar as posições de Dilthey e de Heidegger ao pensamento hermenêutico, explicita que:

\begin{abstract}
Enquanto, partindo de Dilthey, Misch descobre na livre distância com relação a si uma das possibilidades fundamentais da vida, possibilidade na qual o fenômeno da compreensão deve fundar-se, Heidegger, partindo também de Dilthey, vai mais longe: torna-se o iniciador de uma reflexão ontológica radical e revela o pro-jeto (Entwurf) existente em toda compreensão. A compreensão é o movimento da "transcendência". (GADAMER, 1998. Pag. 40)
\end{abstract}

Através da idéia de método fenomenológico de investigação, ${ }^{21}$ a teoria esboçada por Martin Heidegger, questiona a partir de uma dimensão hermenêutica do saber, pois o "ser" nunca vai ser em "essência", mas sempre em "aparência". Por isso, a questão da temporalidade é um ponto chave nas discussões filosóficas propostas por interpretes de Heidegger. O autor de Ser e Tempo, prossegue com as formulações da tradição romântica, visto que

${ }^{21}$ Em Heidegger, "é a partir da necessidade real de determinadas questões e do modo de tratar imposto pelas "coisas em si mesmas" que, em todo caso, uma disciplina pode ser elaborada". Op. Cit. pp. 56. 
acredita que o "ser" busca sempre uma compreensão de si mesmo e do mundo com base na "linguagem" e considerando que a "compreensão funda a interpretação", ${ }^{22}$ que apesar de discutir exaustivamente a temporalidade, não se aprofunda na complexa questão histórica, como sugere Gadamer.

Em Heidegger o que é primeiro na ação filosófica do "ser" não é a "conceituação da história", mas "a interpretação daquele ente propriamente histórico em sua historicidade". ${ }^{23}$ Já Hans-Georg Gadamer reinterpretando Heidegger, vê no papel do historiador uma mediação, pois ele divide a "história" em "história efetiva" e "consciência histórica". A hermenêutica de Gadamer apresenta-se no distanciamento entre o presente e o passado. Temporalidade é mudança. Assim, Gadamer critica a construção de uma "continuidade histórica", dando ênfase na mudança e na temporalidade das coisas, em crítica e renovação também à Wilhelm Dilthey que produzia uma idéia de historicidade como "continuo processo". Para Hans-Georg Gadamer, o passado nunca é completamente passado, pois compõe também a voz interpretativa do presente. Em suas proposições se esta sempre ligado em linguagem à uma "tradição", com isso, o "presente" é sempre habitado por uma "tradição" do "passado". Na leitura de Gadamer, a história, acima de tudo, elucida os "preconceitos", visto que "a consciência moderna assume uma posição reflexiva com relação a tudo que lhe é transmitido pela tradição". ${ }^{24}$ Tudo leva a crer que, em Gadamer a "tradição" fortalece a "compreensão", surgem novas possibilidades de leituras, a "tradição" é algo do passado que continua como "pré-conceito" instituínte do

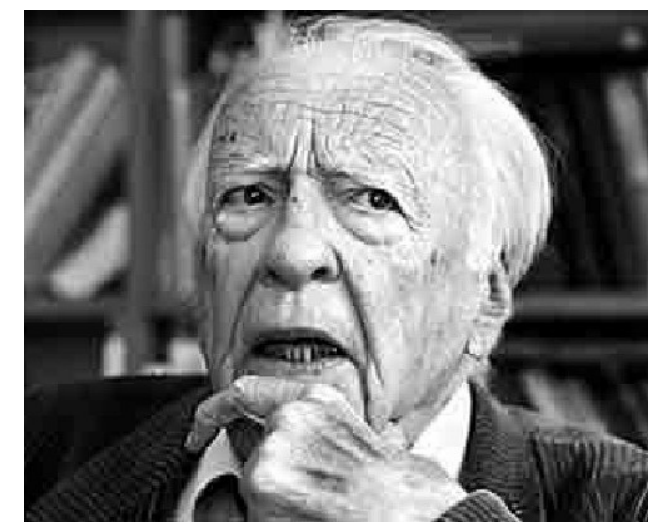

** Hans-Georg Gadamer (1900-2002) presente. Assim, exibe a possibilidade de leitura de "tradição" com referência prévia em exercer, um tipo de "horizonte de interpretação". A história em

\footnotetext{
22 Perceber discussão proposta por Emmanuel Carneiro Leão, na apresentação do texto de Heidegger, que o "ser e tempo" é texto de uma língua. Cf. HEIDEGGER, 2002. Pag. 17.

${ }^{23}$ Aqui, o autor elucida "a contribuição positiva da Crítica da Razão Pura, de Kant". Pois, "a lógica transcendental é uma lógica do objeto a priori, a natureza,enquanto setor ontológico". HEIDEGGER, 2002. Pag. 37.

24 GADAMER, 1998. Pag. 19.
} 
Gadamer é parte de todos como sujeitos e a compreensão do sujeito é de ordem da hermenêutica. Por isso, para Gadamer.

o que interessa ao conhecimento histórico não é saber como os homens, os povos, os Estados se desenvolvem em geral, mas, ao contrário, como este homem, este povo, este Estado veio a ser o que é; como todas as coisas puderam acontecer e encontrar-se aí. (GADAMER, 1998. Pag. 24)

Em contribuição singular ao conhecimento histórico através de uma leitura hermenêutica das ciências sociais, Gadamer apresenta a necessidade de recolhimento material do passado na atividade de se estudar o presente. $O$ Autor do Problema da consciência histórica, sugere que interpretar o passado é fundamental para se pensar o presente de forma critica, vendo como "alienação" primordial, a perda total dos homens de referência ao espaço e a temporalidade. ${ }^{25}$ Contudo, a "ética" continua em discussão com a história e a hermenêutica em seus escritos, dando sentido à importância da "'distância temporal" e do seu significado para a compreensão". ${ }^{26}$

Gadamer consegue esboçar, fundamentalmente, a leitura que enxerga o trabalho de ir ao passado como uma maneira de "desnaturalizar" o presente, pois indo ao passado, o estudioso interpreta as aberturas e falhas do presente o visualizando de fora. Ou seja, busca-se no "bem" do passado as referências das atuais inquietações pessoais do pesquisador.

Gadamer, vê na obra a produção de sentido da própria vida. Suas considerações para com as obras de Dilthey e Heidegger foram significativas, pois ele estende as considerações sobre "consciência histórica" e vê na "existência" o ponto de compreensão hermenêutica que parte da "tensão". O filósofo alemão esclarece que, "a tensão que existe entre a "familiaridade" e o caráter "estranho" da mensagem que nos é transmitida pela tradição é que fundamos a tarefa hermenêutica". ${ }^{27} \mathrm{Em}$ Gadamer, a "situação hermenêutica" é colocada no "coração das coisas".

\footnotetext{
25 Nas proposições de Hans-Georg Gadamer, a temporalidade expressa, sobretudo, um caráter finito existencial através da delimitação histórica do processo compreensivo-interpretativo. É reconhecer a impossibilidade de juízo de razão diante de uma suposta distância temporal. Cf. GADAMER, 1998.

26 Op. Cit. pp. 67.

27 Ibid Ibdem
} 
Mas, por conseguinte, o pensamento hermenêutico de Gadamer ainda é criticado por Jürgen Habermas, que também vê no diálogo a possibilidade de construção do conhecimento. Pois, ao atribuir esclarecimentos sobre o caráter construtivista da razão através da comunicação, através de conceitos sobre razão comunicativa e ação comunicativa, o filósofo e sociólogo alemão, Jürgen Habermas considera que:

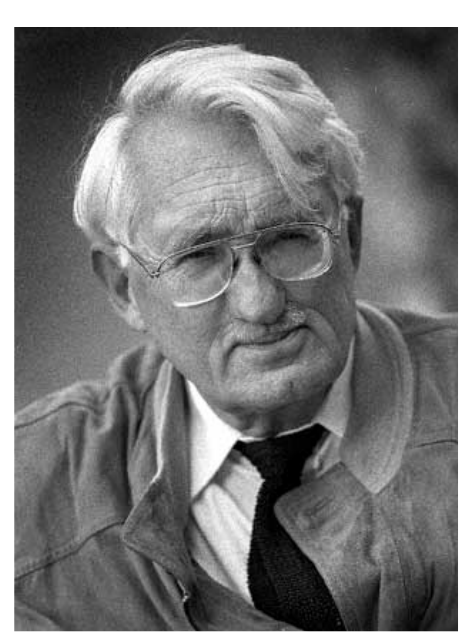

Gadamer vê fundidas num único ponto as tradições vivas e a investigação hermenêutica. A isto se opõe a noção de que a apropriação refletida da tradição rompe a substância naturalística da tradição (uberlieferung) e modifica a posição dos sujeitos nela. Gadamer sabe que as ciências hermenêuticas só se desenvolveram em reação à uma decrescente pretensão de validade das tradições. Se ele, mesmo assim, acentua que as tradições não teriam perdido seu poder pela consciência histórica (p. XV), então ele reveste a crítica justificada à falsa autocompreensão do historicismo com a expectativa injustificada que o historicismo não tenha conseqüências. (HABERMAS, 1987. Pag. 15)

Com uma visão construtivista para o conhecimento, Jürgen Habermas dá crédito às virtuosidades e emancipações da modernidade e elabora uma crítica à idéia de "tradição" e de "pré-conceito", propostas inicialmente por Gadamer em Dialética e hermenéutica: para a crítica da hermenêutica de Gadamer. Em Habermas, a "tradição" de Gadamer dever ser problematizada, pois ela já trás por si mesma, valores conjuntos, que não serão criticados na produção do conhecimento. O autor enxerga que Gadamer não produz um enfoque crítico da linguagem, pois enxergando a hermenêutica das ações como uma constante produção de sentido, acusa a visão de Gadamer como referencial puramente da linguagem, visto que a "tradição" já se autoriza a falar e ser compreendida por si mesma.

Habermas, ao discutir o papel do intérprete em tentar compreender a "tradição", ressalta que, "o preconceito de Gadamer em favor do direito dos preconceitos documentados pela tradição questiona a força da reflexão, que entretanto, confirma pelo fato de que ela pode também rejeitar a pretensão das 
tradições". ${ }^{28}$ Para Habermas a razão é dialógica e dialética, assim o autor em sua crítica hermenêutica considera que, Gadamer produz um monólogo com o "tempo", por isso aposta no devir através da dialética e no desenvolvimento do conceito através da crítica.

Habermas considera que, a "hermenêutica se refere a uma "capacidade" (Vermögen) que adquirimos à medida que aprendemos a "dominar" uma linguagem natural: à arte de compreender um sentido lingüisticamente comunicável e, no caso de comunicações perturbadas, torná-lo inteligível". ${ }^{29}$ A inquietação de Habermas, que vê na pessoa um "ser" totalmente "bom" por "natureza", é de tentar afastar os conhecimentos humanísticos do campo das ciências. Com isso, o filósofo alemão trabalha contra a pretensão de universalidade da hermenêutica e ao temer a sua auto-suficiência ontológica herança do pensamento de Heidegger e Gadamer -, Habermas enxerga que a hermenêutica e a dialética devem fazer parte do método e do debate das ciências sociais. Mas, tais métodos não se apresentam como todo corpus metodológico necessário da escrita, visto que o teórico não negligencia a atenção ao leitor para ter o cuidado de não ultrapassar o método e "recolocá-la ao nível filosófico pela reflexão". Contudo, Habermas com um pensamento construtivista esclarece que "autoridade e conhecimento não convergem". ${ }^{30}$

Por fim, e não menos importante para o prosseguimento da discussão que aqui se propôs, está o historiador alemão, Heinhart Koselleck. Este pensador, que através do estudo da hermenêutica busca pela apreensão de sentido, com base no conceito de "história". Cria a denominação de história conceitual ou história dos conceitos, como instrumentalização do que se convencionou chamar de história intelectual. Koselleck aprimora as considerações sobre a "história moderna", pretendendo desenvolver uma história conceitual a partir da utilização de elementos do campo da estética, da ética e da dialética histórica. Com isso, Heinhart Koselleck, propõe que a história é um gênero de si mesma, com horizontes e delimitações particulares, com problemas e materiais singulares e, com base nas escritas de Hegel, cria uma área da história que chama de história reflexiva. Vale ressaltar que, a

${ }^{28}$ HABERMAS, Jürgen. Dialética e hermenéutica: para a crítica da hermenêutica de Gadamer. Trad. Álvaro Valls. Porto Alegre: L\&PM, 1987. Pag. 17-18

${ }^{29}$ Op. Cit. pp. 26.

30 Op. Cit. pp. 114. 
hermenêutica em Koselleck está inserida na busca em se construir um sentido para a história, enxergando nela - a história - um modelo de erudição filológica.

Ao estudar como se deu o "conceito moderno" de história na Alemanha, Koselleck explicita as "tradições" herdadas da discussão sobre hermenêutica, onde:

El "Esbozo para uma Crítica de la razó histórica [historisch]" de

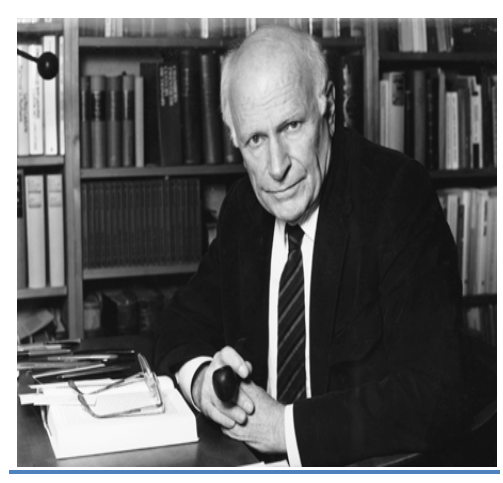

** Heinhart Koselleck (1923-2006) Dilthey, tan rico en matizes, alcanza muy dentro de las ciencias sociales y del espíritu... Con el concepto de "histocidad", la filosofia de la existencia y la hermenéutica hacían suya una categoría apropiada para fundamentar metahistoricamente, por asi decirlo, la relatividad de todo lo histórico, que consequentemente se rebasa a sí misma. ${ }^{31}$ (KOSELLECK, 2004. Pag. 151)

Com isso, a história conceitual de Koselleck, com base hermenêutica e na filosofia existencialista, vê uma circularidade histórica do pensamento, em interpretação das "histórias possíveis" - investigações empíricas -, sem perder de vista as dimensões escatológicas de considerações que surgem no plano de questionamento do pesquisador e interprete da história. Dessa forma, o pensador alemão menciona sobre ocasiões conceituais como o "fim da história" e com base na interpretação da atual escatologia teológica, considera-o possível através do pressuposto "subjetivista" da escrita como tal. Em Koselleck, a história do conceito alcança dimensões de "sentido" ao "não sentido", visto que sua expressão anuncia o começo da "idade moderna".

Para Reinhart Koselleck, a história durante o século XIX entra em uma "relativa estabilidad que se amortizaria después de la modernización, sin coerciones ni pertubaciones al crecimiento". ${ }^{32}$ As proposições do historiador alemão são de que, o conceito não pode ser entendido sem os contextos, o que produz uma ação social do conceito, por assim dizer, uma comunicação -

\footnotetext{
31 "O "Esboço para uma Crítica da razão histórica [historicismo]" de Dilthey, tão rico em matizes, atinge profundamente as ciências sociais e do espírito... Com o conceito de "historicidade", a filosofia da existência e a hermenêutica apóia uma categoria apropriada para fundamentar metahistoricamente, por assim dizer, a relatividade de todo o histórico, que conseqüentemente esteja ultrapassado de si". Grifos nossos. Cf. KOSELLECK, Reinhart. historia/Historia. Trad. Antonio Gómez Ramos. Madrid: Editorial Trotta, S.A., 2004. pp. 151.

${ }^{32}$ A história do século XIX, em Koselleck, encontra uma "relativa estabilidade que se extingue após a modernização, sem coerção ou distúrbios de crescimento". Grifos nossos. Op. Cit. pp. 152.
} 
lembrança de Habermas. A tentativa de Koselleck é de construir um "sentido" comum que vê no conceito já uma interpretação. Por isso, se esforça para compreender o conceito em uma determinada época - temporalidade -, trazendo renovações no pensamento cientifico da contemporaneidade e mapeando as fixações e os deslizamentos dos sentidos. A saber, a "história conceitual' criada por Reinhart Kosellek, se tornou um tipo de instrumentalização escrita da disciplina histórica, que busca a relação hermenêutica entre o conceito e aquilo que ele nomeia.

Contudo, tal empreitada discursiva, envolvendo autores alemães que trataram de forma plausível - para profusão reflexiva da hermenêutica no âmbito das ciências sociais -, sobre a teoria, metodologia e crítica "hermenêutica" e suas relações com a escrita da história, esboça leituras que norteiam o cerne das atuais discussões sobre a disciplina de história. Exemplo, de sua múltipla relação com a escrita da história, lembrar de considerações outras, como Michel de Certeau em: A Escrita da História e Paul Ricoeur em: Tempo e Narrativa. Torna-se relevante revelar que, nos dias atuais, o conceito de história está envolto em formulações diversas que pressupuseram alguns historiadores e filósofos. Visto em sua pluralidade, a história caminha em defesa da "tradição" ou "ponderação" de um determinado "estilo" ou "método específico", pois as considerações contemporâneas relacionam a história tanto ao "gênero literário", à "narrativa", como ao "conceito". Enfim, tal relação da história atribuída à filosofia hermenêutica pode possibilitar a ampliação dos horizontes históricos em seu alcance atribuído às múltiplas leituras de temas e abordagens. Trata-se de uma discussão de fundamental importância para maturação da idéia de se fazer história, estando a produzir insistentemente a história do tempo presente. Por isso, o caráter de temporalidade enunciado por Martin Heidegger em suas formulações sobre o "ser" ganha dimensões diversas quando abordados por outros estudiosos, a exemplo de Hans-Georg Gadamer e Jürgen Habermas. Tal temporalidade entrelaça-se na descrição interpretativa construída através do imaginário local (lembrar Cornelius Castoriadis em: A Instituição Imaginária da Sociedade) delimitando os conceitos produzidos através do tempo. Um tipo de relatividade histórica perspectivista, como sugere Reinhart Koselleck, ao apresentar a história como 
conceito, um "guia moderno" com suas "funções sociais e políticas". Pois, para o autor de historia/Historia:

\begin{abstract}
Uma vez que la "historia" se había convertido en un concepto de reflexión que, explicando, fundamentando y legitimando, hace de mediadora entre el futuro y el passado, podía percibirse esta tarea suya de modo diferente. Las naciones, las classes, los partidos, las sectas u otros grupos de interés podían, tenían inclusoque invocar la historia en tanto que una deducción genética de su respectiva posición les ortogaba títulos legales en la estructura de acción política o social. ${ }^{33}$ (KOSELLECK, 2004. Pag. 109.)
\end{abstract}

\title{
Referências Bibliográficas
}

1. GADAMER, Hans-Georg. O problema da consciência histórica. Org. Pierre Fruchon. Trad. Paulo César Duque Estrada. Rio de Janeiro: Editora Fundação Getúlio Vargas, 1998.

2. HABERMAS, Jürgen. Dialética e hermenêutica. Trad. Álvaro Valls. Porto Alegre: L\&PM, 1987.

3. HEIDEGGER, Martin. Ser e Tempo. Trad. Maria Sá Cavalcante Schuback. 12 ${ }^{\mathrm{a}}$ Edição. Editora Vozes: universidade São Francisco, 2002.

4. KOSELLECK, Reinhart. historia/Historia. Trad. Antonio Gómez Ramos. Madrid : Editorial Trotta, S.A., 2004.

5. SCHLEIERMACHER, Friedrich D.E. Hermenêutica: Arte e técnica da interpretação. Trad. Celso Reni Braida. Petrópolis RJ: Vozes, 1999.

6. WEBER, Marx. A "objetividade" do conhecimento nas ciências sociais. Trad. Gabriel Cohn. São Paulo: Ática, 2006.

${ }^{* *}$ Imagens da Internet:

1. Friedrich Schleiermacher (1768-1834): http://www.infed.org/images/people/schleiermacher wc.jpg

2. Dilthey, Wilhelm (1833 - 1911): http://www.absoluteastronomy.com/topics/Wilhelm Dilthey

3. Marx Weber (1864-1920): http://metamorficus.blogspot.com/2008/05/o-crculo-max-weber-deheidelbreg4.html

4. Martin Heidegger (1889-1976): http://hermeneuticajuridica.files.wordpress.com/2008/09/heidegger1.jpg

5. Hans-Georg Gadamer (1900-2002): http://www.phenomenologycenter.org/images/gadamer1.jpg

6. Jürgen Habermas (1929): http://davelah.files.wordpress.com/2009/05/habermas.jpg

7. Heinhard Koselleck (1923): http://www.fotomarburg.de/aktuelles/pressemitteilungen/Koselleck1.jpg

33 "Uma vez que a "história" havia se tornado um conceito de reflexão que, explicando, fundamentando e legitimando, faz uma mediação entre o futuro e o passado, a sua tarefa pode ser percebida de forma diferenciada. As nações, classes, partidos, seitas ou outros grupos de interesses poderiam, teriam mesmo que invocar a história como uma dedução genética de suas respectivas posições lhes concediam o título legal para a estrutura da ação política ou social”. Grifos nossos. Op. Cit. Pag. 109. 